\title{
FOREBRAIN SIZE AND INNOVATION RATE IN EUROPEAN BIRDS: FEEDING, NESTING AND CONFOUNDING VARIABLES
}

by

\author{
NEKTARIA NICOLAKAKIS and LOUIS LEFEBVRE $\mathbf{E}^{1,2,3)}$ \\ (Department of Biology, McGill University, Montréal, Québec, H3A 1B1 Canada)
}

(Acc. 20-VI-2000)

\begin{abstract}
Summary
Previous work has shown a positive correlation between relative forebrain size and feeding innovation frequency, corrected for species number, over different taxonomic groups of birds. Several confounding variables could account for this relationship: ornithologists could notice and report innovations more often in certain taxa because of biased expectations, greater research effort, editorial bias in journals or large population sizes of the taxa. The innovationforebrain correlation could also be spuriously caused by phylogeny or juvenile development mode. We examined these possibilities by entering species number per taxon, population size, number of full length papers, expectations (assessed by a questionnaire), journal source and development mode in multiple regressions that also included relative forebrain size. We did this with and without phylogenetic corrections and tested two behavioural categories, feeding and nesting, where flexibility and learning are clearly thought to differ, but confounds should have similar effects. Through an exhaustive survey covering 30 years in 11 journals, a total of 683 innovations was gathered for the northwestern part of Europe, 507 for feeding and 176 for nesting. Species number per taxon was the only significant confound for both feeding and nesting reports; as predicted, forebrain size was a second significant predictor for feeding innovations, but not for nesting. The frequency of feeding innovations in the short notes of ornithology journals thus appears to be a valid and reliable way to operationalise behavioural flexibility in birds.
\end{abstract}

\footnotetext{
1) To whom reprint requests should be sent; e-mail address: louis_lefebvre@maclan.mcgill.ca

2) Funding for this work was provided by a grant from NSERC (Canada).

3) We are grateful to Danielle Choquette for collating a part of the innovation corpus, Marc Trudel and Frédérique Courtois for statistical advice and Sarah Timmermans for help with the forebrain data. We are also indebted to Patrick Whittle, who conducted the initial review of feeding innovations in Europe.
} 


\section{Introduction}

When birds show behaviours that are unusual with respect to their species norm, ornithologists routinely report these in the short notes section of avian journals. Most often, the notes concern new feeding behaviours, sightings of vagrant individuals away from the species' range or unusual materials and places used for nesting. Lefebvre et al. (1997, 1998) have proposed that these notes, when exhaustively collated, may be a good way to quantify taxonomic differences in behavioural flexibility: all other things being equal, a taxonomic group (e.g. the order Passeriformes; Wyles et al., 1981 ) that shows more opportunism, more generalism, more learning and innovation, should appear more often in these short notes. For novel feeding behaviours, a consistent pattern of taxonomic differences has been found in birds of Europe, North America (Lefebvre et al., 1997), Australia and New Zealand (Lefebvre et al., 1998): once species diversity is taken into account (Passeriformes will appear in more notes because there as so many species in this order), groups like the Corvida, Ciconiida and Accipitrida show high rates of innovation, while Phasianida, Columbiformes and Apodiformes do not.

Part of this variation is associated with the relative size of the forebrain. Avian taxa characterized by a relatively large forebrain (e.g. Holarctic Corvida and Piciformes, Australian Psittaciformes) tend to show higher feeding innovation rates (Lefebvre et al., 1997; 1998); a similar relationship between innovation rate and relative size of the neocortex has recently been shown in primates (Reader \& Laland, 1999). Avian species that have successfully established themselves in new areas have a relatively larger forebrain and a higher innovation rate than species who have failed to do so (Sol \& Lefebvre, in press). Similar links between the complexity of a behaviour and the size of its neural substrate in birds and mammals have been established for spatial memory (reviewed by Sherry et al., 1992; Balda et al., 1996), song repertoires (de Voogd et al., 1993; Brenowitz \& Kroodsma, 1996), social networks (reviewed by Dunbar, 1998), tactical deception (Byrne, 1993), social learning and tool use (Reader \& Laland, 1999).

Innovation reports taken from short notes are anecdotal, a data-gathering technique that is often criticized for its subjectivity and dependance on ad libitum observations (reviewed in Mitchell et al., 1997 and the open peer 
commentary following Whiten \& Byrne, 1988). Previous papers on feeding innovation s have attempted to minimize this problem by avoiding cognitive interpretations and using independent readers blind to the hypothesis, yielding high levels of inter-judge agreement (Lefebvre et al., 1997, 1998). However, short notes may nevertheles s carry a hidden bias, leading to a spurious relationship between innovation rate and relative forebrain size. One way to deal with this problem is to compare short note categories that are thought to involve different degrees of behavioural flexibility. Nest building is a good candidate for comparison with feeding: it is the third most frequent category in short notes (after ranging and feeding) and is thought to be more constrained than feeding. A review by Hansell (1984) concludes on the 'substantial degree of genetic control' (p. 218) over nest building and the paucity of evidence for modification of this behaviour through experience, with at most a sharpening of pre-programmed tendencies through practice (Collias \& Collias 1964). Sargent (1965) suggests that 'innate predisposition s tend to bias birds in favor of species-specific nesting materials and situations, with experience playing only a limited role' (p. 59). Nesting is also more specialized than feeding: there is, for example, no nesting equivalent of the omnivore strategy in feeding. Given these differences, the information processing capacity associated with a larger forebrain should affect feeding more than it should nesting; in contrast, there is no reason to expect that observer bias and chance will act differentially on the two behavioural categories.

A second problem posed by the innovation/forebrain link is its potential dependance on confounding variables. The most obvious confound, species number per taxon, was removed in previous work, but variables like population size, reporting bias or research effort could also affect the relationship between innovation frequency and forebrain size: do Passerida, for example, show a high innovation frequency because the parvorder contain so many species or because it is intensively studied by ornithologists, who both expect and report more innovative behaviours in this highly populous group? Phylogeny could also be an important confounding variable: a high innovation rate and large forebrain could co-occur in Passerida and Corvida, on the one hand, and Accipitrida and Falconida, on the other, because of common ancestry (Harvey \& Pagel, 1991). Taxonomic levels chosen for previous analyses were very general, i.e. classical orders (Lefebvre et al., 1997), which are often equivalent to molecular parvorders (Lefebvre et al., 1998); even at 
this remote level, however, genetic distances between taxa vary considerably (Sibley \& Ahlquist, 1990).

In this paper, we use the largest regional data set available for short notes, that of northwestern Europe, the region that is also best covered by the forebrain size sample of Portmann (1947). Through an exhaustive survey of 30 years (1970-1999) in 11 journals, we increase the data base gathered for Great Britain by Lefebvre et al. (1997) on feeding and apply the same procedure to nesting reports. If nesting is more tightly constrained than feeding and if innovation reports are a valid estimate of the behavioural flexibility allowed by larger information processing structures, then only feeding should be associated with forebrain size. Secondly, if the association is not caused by common ancestry, independent contrasts on the European data should yield results similar to previously reported trends at the level of classical orders (Lefebvre et al., 1997). Thirdly, if population size, reporting bias and research effort are responsible for variation in the number of short notes published per avian taxon, they should account for the previously reported effects of species number and forebrain size when entered with them in multiple regressions. We estimate population size per taxon from the recent Atlas of European Birds (Hagemeijer \& Blair, 1997), reporting bias by a questionnaire given to professional ornithologists and research effort by the taxonomic distribution of full length papers in the journals where our innovation s were collated.

Finally, we look at the effect of journal source on our conclusions: in Europe, the best source for innovations is British Birds, which contributes approximately $70 \%$ of our data base. Contrary to other journals, many of the short notes in British Birds are submitted by non-academics, albeit after careful review (and frequent printed comment) by an eight-member Behaviour Notes panel. We thus separate our innovation data into two categories, British Birds vs all other journals, to determine if the importance of the former journal and its particular editorial policy have a biasing effect on the innovation/forebrain correlation.

\section{Methods}

The short notes sections of Ibis, Bird Study, British Birds, Scottish Birds, Ornis Scandinavica/Journal of Avian Biology, Ornis Fennica, Ardea, Die Vogelwarte (English-language papers and summaries only), Alauda, Nos Oiseaux and Aves were exhaustively reviewed for 
any mention in the title or text itself of a feeding or nesting innovation. The first three journals cover England and Wales, while the others respectively cover Scotland, the Scandinavian countries, Finland, the Netherlands, Germany, France, and the French-speaking areas of Switzerland and Belgium. Approximately 11400 short notes were scanned in the journals for the period 1970 to 1999 (except Aves where the last year available to us was 1981). A total of 683 innovations was found over the 30 years, 507 for feeding and 176 for nesting; a complete list of the innovations is available upon request. Of the feeding innovations, 124 were identical to the ones used in Lefebvre et al. (1997); 228 were gathered by a second, independent reader (DC) for 1973-1982 and 1993-1997 in British Birds and Scottish Birds, and for 1970-1997 in Alauda and Nos Oiseaux. The remaining 155 innovations were collated by a third reader (LL). The use of independent readers allowed us to calculate inter-judge agreement, an important control given the nature of our data collection technique. For nesting, 124 of the innovations were collated by NN for the 1977-1999 period in British Birds and Scottish Birds, as well as in Aves (1970-1981) and in Die Vogelwarte (1970-1999); a second, independent reader (DC), covering British Birds and Scottish Birds for 1970-1976, Alauda, Nos Oiseaux, and Ornis Fennica, Ornis Scandinavica/Journal of Avian Biology, Ardea, Bird Study, and Ibis for 1970-1999, again allowed us to calculate inter-judge agreement for this behaviour.

As in previous work (Lefebvre et al., 1997, 1998), a feeding innovation was defined as either the ingestion of a new food type or the use of a new foraging technique. For a given report, the food item or foraging technique had to be stated (or in a few cases, clearly implied) by the author to be unusual for the species and/or the author had to state that this was the first known published report of the behaviour. To avoid subjective bias in data collection, we based our decisions on statements made by the authors rather than our own opinion of the reports, looking for key words like 'unusual', 'unknown', 'rare', 'opportunistic', 'strange', 'not noted before', 'not recorded', 'first report'. When a report featured several species, we credited each one with a feeding innovation. When the same behaviour was mentioned more than once in the literature for a given species, we kept only the oldest report and counted the behaviour as a single innovation. When a report stated that a behaviour, although unusual had been noted by other authors, we did not include it. Nesting innovations were defined as either the use of an unusual material or site. Some of the short notes we scanned concerned unusual timing of nesting behaviour; we excluded these cases, however, since they are likely to be more affected by hormonal variables (the major determinants of nest timing) than information-processing, thus biasing the data in favour of our hypothesis. For nesting, we searched for the same key words as we did for feeding innovations and used the same multiple entry rule when two or more species were featured in the same report. Once again, reports of identical behaviours for the same species were only considered once. Table 1 presents examples of the nesting innovations found, including the descriptors taken verbatim from the original reports that justify the novelty of the observation.

For each behavioural category, we tabulated the number of innovations per taxonomic group, using molecularly-defined taxa (Sibley \& Monroe, 1990) that were as close as possible to the classical orders used by Lefebvre et al. (1997). In approximately half the cases, this corresponds to molecular orders; in the other half, the taxon corresponds to what Sibley \& Monroe call 'parvorders', a division that is particularly useful for the new molecular orders that include very large numbers of species, i.e. Passeriformes and Ciconiiformes. In three cases (Grui, Ralli and Caprimulgi), we used Sibley \& Monroe's 'suborder' and, in one case (Pteroclides), 'infraorder'. In the rest of this paper, we will use the terms 'taxon' and 
TABLE 1. Examples of nesting innovations in birds of northwestern Europe

\begin{tabular}{|c|c|c|}
\hline Species & Innovation & Reference \\
\hline Golden eagle & $\begin{array}{l}\text { nesting on grouse moors; unlikely be- } \\
\text { cause of human persecution }\end{array}$ & Watson, 1982 \\
\hline Common teal & nesting on ledges; unusual & Meek \& Little, 1980 \\
\hline Black guillemot & $\begin{array}{l}\text { nesting in a building sited in an area of } \\
\text { heavy industrialization; unusual site, no } \\
\text { record }\end{array}$ & Carnduff, 1981 \\
\hline Carrion crow & $\begin{array}{l}\text { nest made from left-over ends of fenc- } \\
\text { ing wire; unusual }\end{array}$ & Mitchell, 1985 \\
\hline Eurasian hobby & nesting on a pylon; no records & Trodd, 1993 \\
\hline Eurasian siskin & $\begin{array}{l}\text { nesting in a hanging flower pot; unusual } \\
\text { nest site }\end{array}$ & Billett, 1989 \\
\hline Common moorhen & nest cup composed of polythene & Dean, 1992 \\
\hline Willow ptarmigan & $\begin{array}{l}\text { nest made of straw; exceptional in the } \\
\text { material used and its thickness }\end{array}$ & Watson, 1977 \\
\hline Eurasian blackbird & nesting in a commuter station & Montier, 1980 \\
\hline Winter wren & $\begin{array}{l}\text { seen excavating nest; no mention of } \\
\text { wrens excavating cavities }\end{array}$ & Harper, 1991 \\
\hline Common starling & $\begin{array}{l}\text { seen excavating nest holes in sand } \\
\text { dunes; first recorded instance }\end{array}$ & Summers, 1989 \\
\hline Blue tit & $\begin{array}{l}\text { seen using house martin nest; no other } \\
\text { records }\end{array}$ & McNeil, 1992 \\
\hline Common kestrel & $\begin{array}{l}\text { nesting on an urban chimney; interest- } \\
\text { ing }\end{array}$ & Smith, 1992 \\
\hline Common kingfisher & nesting in peat-cuttings; no records & Limbert, 1991 \\
\hline Common woodpigeon & $\begin{array}{l}\text { nesting on sea cliffs and inside build- } \\
\text { ings; exceptional, atypical }\end{array}$ & Rebecca, 1988 \\
\hline
\end{tabular}

Terms in italics are taken verbatim from original papers and indicate novelty.

'taxonomic group' to refer to the categories in Table 2. As in previous papers (Lefebvre et al., 1997, 1998), we excluded the nocturnal owls (suborder Strigi) from our study, since innovations in this group are almost never witnessed, but instead inferred from fecal evidence. To calculate species per taxon, we used a recent atlas of the breeding birds of Europe (Hagemeijer \& Blair, 1997), excluding vagrants and species found only outside the zone covered by our 11 journals, e.g. southern Spain or the Balkans.

Innovation frequencies per taxon were $\log$ transformed $(\ln [$ freq +1$])$ because of their non-normal distribution: many groups yield very small frequencies, while a few groups yield very large ones (e.g. Passerida: 152 feeding innovations, 84 nesting innovations). In contrast to previous work on feeding innovations in Europe (Lefebvre et al., 1997), we factored out species per taxon (also ln transformed due to the presence of very small and very large values) using partial correlations instead of $\chi$ values; $\chi$ is not normally distributed (positive values are likely to be much larger than negative ones) and partial correlations are a much more standard way of removing the effects of a confounding variable (Lefebvre et al., 1998). We 
TABLE 2. Nesting and feeding innovation frequencies for 21 bird taxa

\begin{tabular}{lrrrr}
\hline Taxonomic group & Nesting innovation frequency & \multicolumn{2}{c}{ Feeding innovation frequency } \\
\cline { 3 - 5 } & & BB $^{\mathrm{a}}$ & others $^{\mathrm{b}}$ & total \\
\hline Phasianida & 2 & 2 & 2 & 4 \\
Anseriformes & 8 & 15 & 4 & 19 \\
Piciformes & 1 & 10 & 3 & 13 \\
Upupiformes & 0 & 0 & 0 & 0 \\
Coraciiformes & 1 & 2 & 0 & 2 \\
Cuculiformes & 0 & 0 & 1 & 1 \\
Apodiformes & 0 & 1 & 1 & 2 \\
Caprimulgi & 0 & 0 & 0 & 0 \\
Columbiformes & 6 & 3 & 0 & 3 \\
Grui & 1 & 1 & 0 & 1 \\
Ralli & 3 & 10 & 2 & 12 \\
Pteroclides & 0 & 0 & 0 & 0 \\
Scolopacida & 1 & 24 & 4 & 28 \\
Charadriida & 18 & 49 & 28 & 77 \\
Accipitrida & 7 & 18 & 25 & 43 \\
Falconida & 16 & 22 & 17 & 39 \\
Podicipedida & 2 & 4 & 2 & 6 \\
Sulida & 2 & 4 & 3 & 7 \\
Ciconiida & 7 & 22 & 13 & 35 \\
Corvida & 17 & 44 & 19 & 63 \\
Passerida & 84 & & & 152 \\
Total & 176 & 37 & 507 \\
\hline
\end{tabular}

${ }^{\text {a }}$ Innovations found in British Birds.

${ }^{\mathrm{b}}$ Innovations found in all other European journals.

also factored out population size per taxon using the same method. For each of the European species, we took the median value of the population number (ln converted as well) given by Hagemeijer \& Blair (1997) and summed all species in a taxon, again excluding vagrants and birds found outside the range covered by the journals.

Research effort was estimated from full length papers published in the same journals we surveyed for short notes. Either one or two issues per volume, depending on publication frequency, were randomly sampled for each journal and all species studied in field-based full length papers in the issue were noted. We excluded studies done in captivity or based on data from the literature, since this kind of research cannot yield innovation reports; we also excluded zoological surveys that simply name species present in a particular area, since they focus on identification, not behaviour, and can potentially skew taxonomic frequencies due to the large number of species in each paper. A total of 1214 species entries were obtained. Reporting bias was estimated from a questionnaire. Professional ornithologists attending a national meeting were asked to assign a score between 1 and 5 to their likeliness to notice 
and report a new food type or foraging technique in each of the taxonomic groups. Mean scores per taxon were calculated from the 25 questionnaires returned to us.

As in previous papers, we used Portmann (1947) as the source of the forebrain data. Portmann's work covers 140 avian species in 119 genera. His data are presented as ratios of forebrain weight for a given species divided by the brainstem weight of a Galliforme of equivalent body weight; Portmann calls the latter measure the basal index, while the forebrain ratio is called the hemispheric index. Multiplying Portmann's basal index by his hemispheric index yields forebrain weight. Using the body weights also provided by Portmann, we ran log$\log$ regressions on the 119 genera (Strigi included), then calculated mean residual deviations for the taxa defined above.

Two statistical approaches were used: (1) multiple regressions (SYSTAT) that assumed, as did Lefebvre et al. (1997), that orders, parvorders and suborders are taxonomically remote enough for common ancestry to be negligible; and (2) independent contrasts (CAIC, Purvis \& Rambaut, 1995). The latter technique is based on the construction of a phyletic tree using average linkage clustering of DNA-DNA hybridization distances given in Sibley \& Ahlquist (1990). The tree is then used in a phylogenetically-controlled test performed by an independent contrast program; the technique identifies sets of independent comparisons within the branching pattern of the phylogenetic tree. Independent contrasts are created by comparing the values of sister taxa; values for ancestral nodes in the phylogeny are estimated by averaging the values of extant taxa. The independent variables in the multiple regressions were (1) number of species per taxon, (2) population size, (3) number of full length papers, (4) mean score for likeliness to report and (5) mean residual forebrain size. We also added a known confound of avian brain size, juvenile development mode (Portmann, 1946; Bennett \& Harvey, 1985), which was entered as a dichotomous variable (nidicolous vs nidifugous, based on Sibley \& Monroe, 1990). In the multiple regressions and the independent contrasts, we predict a significant partial correlation between feeding innovation frequency and mean residual forebrain size, but no such correlation for nesting report frequency. With the 21 taxonomic categories used, the probability of detecting a difference at the 0.05 level between a partial correlation for feeding (expected $r=0.700$, based on Lefebvre et al., 1997) and no partial correlation for nesting (expected $r=0.000$ ) is 0.80 (Cohen, 1988).

\section{Results}

Table 2 presents the frequency of nesting and feeding innovations found for the 21 taxa. As in previous papers, groups like Passerida, Corvida, Accipitrida and Charadriida show high frequencies, while Phasianida and Columbiformes show low frequencies. Our data collection procedure is highly reliable: frequencies per taxon obtained by the independent readers are very similar for both nesting $(r=0.827, p<0.001)$ and feeding $(r=0.910, p<0.001)$.

The best predictor of innovation frequency per taxon is species number, which respectively accounts for $84 \%(p<0.001)$ and $68 \%(p<0.001)$ of the feeding and nesting innovations. None of the other potential confounds 
come out significant in the multiple regressions. Neither mode of juvenile development (partial $r=0.257, p=0.304$ ), population size (partial $r=-0.194, p=0.441$ ), research effort (partial $r=0.338, p=0.171$ ) nor reporting bias (partial $r=0.382, p=0.117$ ) predict feeding innovation frequency when species number is present in the model (overall $r^{2}$ of the multiple regression $=0.879, F_{2,17}=70.167, p<0.001$ ). Relative forebrain size is the only other variable that remains significant (partial $r=0.564$, $p=0.012$ ). When regressions are run on the split data sets from the two journals sources, there is a significant difference $(p=0.005)$ in innovation frequency per taxon between British Birds ( $N=346$ innovations $)$ and all other journals $(N=161)$. Taken separately, however, both journal sources yield significant effects of relative forebrain size with species number also included in the multiple regression (British Birds: partial $r$ of forebrain size $=0.543, p=0.020$; all other journals, partial $r=0.500, p=$ 0.034 ), indicating that divergence between sources does not invalidate the innovation-forebrai $n$ link.

For nesting innovations, the only significant predictor in the multiple regression is the number of species per taxon (partial $r=0.821, p<0.001$; overall $r^{2}$ of the multiple regression $=0.678, F_{1,19}=43.166, p<0.001$ ). Neither forebrain size (partial $r=0.244, p=0.313$ ) nor juvenile development mode (partial $r=0.386, p=0.103$ ) reach significance thresholds for the nesting data; the same is true for population size (partial $r=0.141$, $p=0.565$ ), research effort (partial $r=0.124, p=0.613$ ) and reporting bias (partial $r=-0.206, p=0.397$ ). The non-significant association between forebrain size and nesting is consistent with our prediction, but the partial correlations of forebrain size on nesting (0.244) and feeding (0.564) do not differ enough to reach statistical significance ( $t$ test on the coefficients of the partial correlations $=0.60$, df $=34$, NS). Furthermore, taxonomic trends in nesting and feeding reports are significantly correlated: residuals of the two sets of frequencies, each regressed against species number per taxon, yield an $r$ of $0.482(p=0.027)$. These residuals are illustrated in Fig. 1, along with mean residual forebrain size.

Independent contrasts show the link between forebrain size and feeding innovation rate cannot be attributed to common ancestry: results from CAIC reveal a significant association of the two variables once phyletic effects have been removed (partial $r=0.538, p=0.018$ ). The independent contrasts for nesting also confirm the results obtained on phyletically-uncorrecte d taxa; 
A

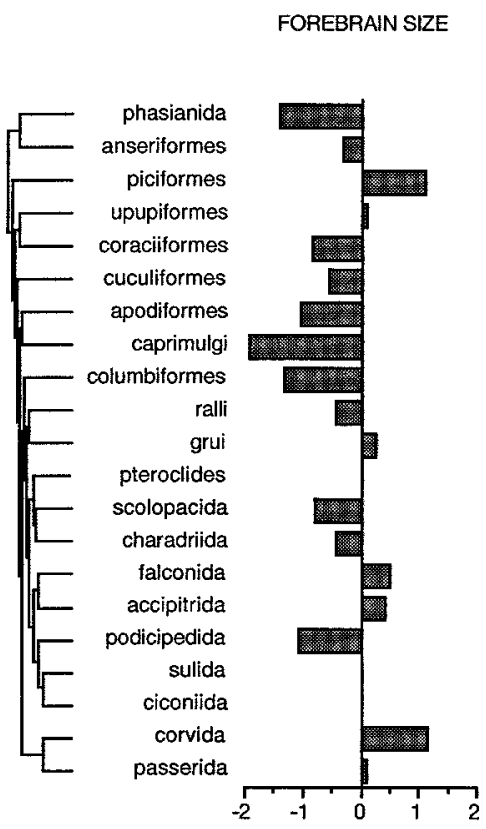

C

RESIDUAL FEEDING INNOVATION FREQUENCY

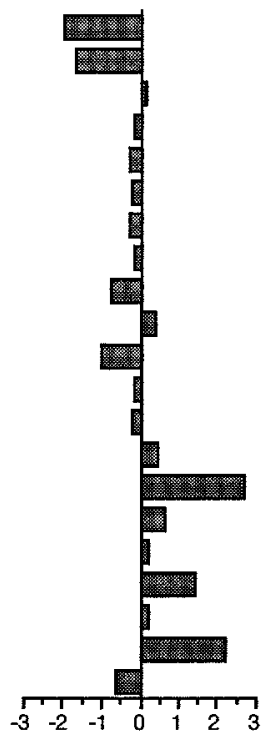

D

RESIDUAL NESTING INNOVATION FREQUENCY

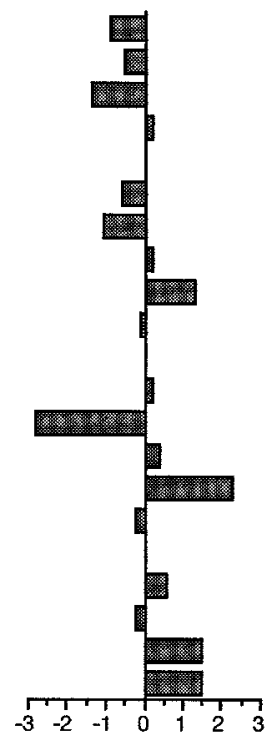

STANDARDIZED RESIDUAL

Fig. 1. (A) Phyletic tree for the taxonomic groups used in this study based on DNA/DNA hybridization distances in Sibley \& Ahlquist (1990). (B) Standardized residual of forebrain size regressed against body weight. Standardized residual of innovation frequency regressed against species number per taxon for feeding (C) and nesting (D).

as in the multiple regressions presented above, the effect of forebrain size on nesting reports is non-significant (partial $r=0.216, p=0.373$ ). As in the preceding analyses, no other variables come out significant in the multiple regressions conducted on independent contrasts.

Figure 2 illustrates the taxonomic trends in the different confounding variables. If we reverse the logic of our earlier multiple regressions and now enter research effort or population size as the dependent variable and all other factors as independent ones, we find that species number is the only significant predictor for both variables, explaining respectively 52 and $90 \%$ of their variance. Taxa that contain more individuals than would be expected on the basis of species number (positive residuals in Fig. 2a) 
A

RESIDUAL

POPULATION SIZE

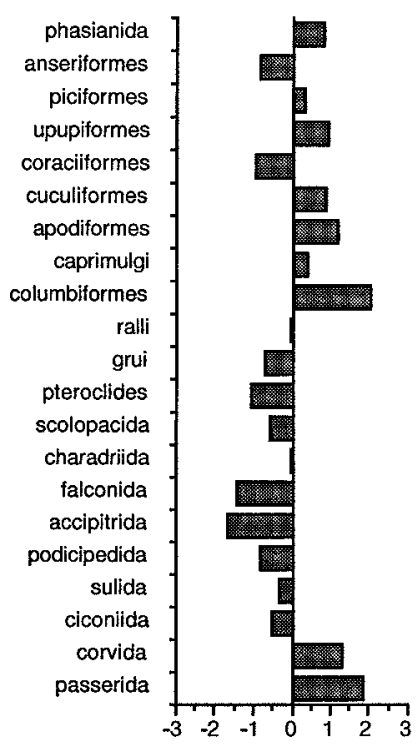

B

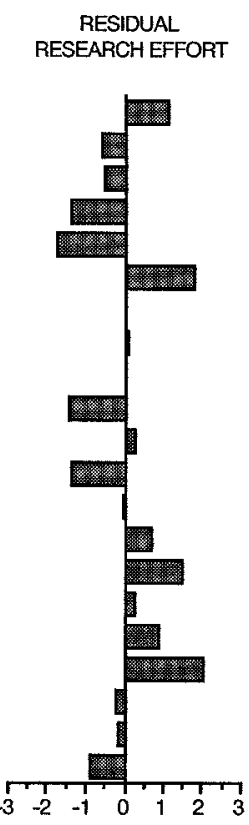

C

REPORTINGBIAS

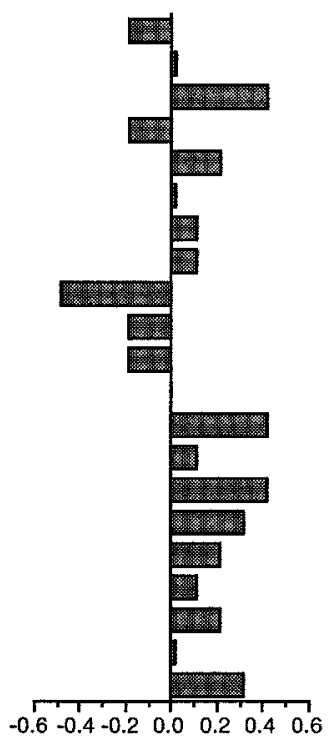

STANDARDIZED RESIDUAL

Fig. 2. Standardized residual of population size (A) and research effort (B) per taxon, regressed against species number. (C) Reporting bias per taxon, expressed as the difference between the overall mean and the mean score for each taxon.

are the Passerida, Corvida and Columbiformes, while taxa that contain relatively fewer individuals (negative residuals in Fig. 2a) are groups like the Accipitrida and Falconida. Taxa like Cuculiformes and Sulida are studied more often than would be expected on the basis of species number (positive residuals in Fig. 2b), while groups like Coraciiformes and Ralli are studied less often (negative residuals in Fig. 2b). The third confounding variable, reporting bias, is illustrated in Fig. 2c as relative mean score, standardized around the grand mean for all taxa to make it visually compatible with other variables. The taxa where ornithologists say they would be most likely to notice and report an innovation are the Scolopacida, Falconida and Piciformes, while the taxon where this is least likely is Columbiformes. In multiple regressions, the best predictor of reporting bias is innovation frequency. 


\section{Discussion}

Of the six potential confounding variables examined in this study - population size, research effort, reporting bias, journal source, juvenile development mode and common ancestry - none account for the correlation between innovation frequency and relative forebrain size. A very similar result was obtained in a recent study of North America and Australia (Lefebvre et al., in prep); as in Europe, forebrain size and species number per taxon were the only significant predictors of innovation frequency in multiple regressions that included research effort, journal source, reporting bias, juvenile development mode, common ancestry and an additional measure of differential interest on the part of ornithologists, the taxonomic distribution of photographs in birding magazines. Species number per taxon thus appears to be the only confound of innovation frequency in the three zones studied up to now. Once frequency is corrected for number of species, innovative bird groups can otherwise be predicted by the relative size of their forebrain: birds with a relatively large neural substrate, such as the corvids, are more opportunistic than the smaller-brained pigeons, pheasants, and nightjars, and produce a greater number of innovations .

As predicted, short notes of unusual nesting behaviours do not follow the trend found for feeding. Number of species per taxon is the only significant predictor here, while forebrain size is non-significant. The failure of the nesting/forebrain relationship to reach significance is unlikely to be due to sample size $(N=176)$ : the feeding sub-sample taken from all journals other than British Birds $(N=161)$, despite being smaller than the sample for nesting, yields a significant correlation with forebrain size. The nonsignificant effect of forebrain size on nesting is consistent with the literature, which emphasizes the pre-programmed aspect of this behaviour, rather than its dependance on information-processing and behavioural flexibility. Three results nevertheless suggest some caution here. First, the $t$ test on differences between partial correlations for nesting and forebrain size, on the one hand, and feeding and forebrain size, on the other, is far from significant. Secondly, the correlation between nesting innovation rate and forebrain size is still positive, even if non-significant. Third, the residuals of feeding and nesting, once regressed against species number per taxon, are significantly correlated, with groups such as Charadriida, Falconida and Corvida showing positive values in Fig. 1 for both feeding and nesting, while Cuculiformes and 
Anseriformes produce fewer feeding and nesting innovation s than predicted by species number. Until further work is done, the data thus offer only ambiguous support for the prediction tested in our study.

Several interesting trends emerge when the potential confounds are treated as dependent variables. The first surprising result is the very high proportion of variance $(90 \%)$ in full length paper frequency that is explained by species number per taxon. It is as if an 'ideal free distribution' determines a large part of this variable, with research effort being more or less proportional to the diversity of taxa. Deviations from this ideal free distribution (Fig. 2a) could reflect factors such as conservation needs, with Falconida, for instance, showing higher residuals than Columbiformes. The effect of species number on population size is much smaller ( $52 \%$ of the variance), although it is again the only significant predictor in our models. The second surprising result is that of reporting bias, which is best predicted by innovation frequency; this is all the more surprising because the converse is not true, i.e. innovation frequency cannot be predicted by reporting bias when forebrain size and species number are also included with it in multiple regressions. This suggests that ornithologists expect to see in birds the trends they read in the literature, but do not in turn bias their reports on the basis of these expectations. Added to the results on photo frequency in North America and Australia, our data thus suggest that feeding innovation rate is a property of birds, not of the ornithologists that study them.

Coupled with a recent study on North America and Australia (Lefebvre et $a l$., in prep), this paper demonstrates that the relationship between forebrain size and feeding innovation rate, corrected for species number per taxon, cannot be accounted for by the confounding variables studied up to now. Innovation rate has been linked to neural substrate size in both birds and primates (Reader \& Laland, 1999), suggesting that the trend could be general. As a measure of flexibility, innovation rate is quantitative, ecologically valid because it is gathered from field observations and as easily available for a broad range of taxa as are body weight and life history data. It avoids the limited taxonomic coverage of comparative learning studies, as well as the often arbitrary nature of the tasks and the potential dependance of results on contextual variables that can favour one species over another. The disadvantages of the measure (largely due to its anecdotal basis) can be minimized if cognitive interpretations of innovation reports are avoided, inter-judge reliability is assessed and potential confounds removed. For the 
moment, feeding innovation rate appears to be a valid and reliable way of operationalising behavioural flexibility in the field.

\section{References}

Balda, R.P., Kamil, A.C. \& Bednekoff, P.A. (1996). Predicting cognitive capacity from natural history, examples from four species of corvids. - Curr. Ornithol. 13, p. 33-66.

Bennett, P.M. \& Harvey, P.H. (1985). Relative brain size and ecology in birds. - J. Zool. Lond. 207, p. 151-169.

Billett, A.E. (1989). Unusual nest-site of siskin. — Br. Birds 82, p. 81.

Brenowitz, E.A. \& Kroodsma, D.E. (1996). The neuroethology of birdsong. — In: Ecology and evolution of acoustic communication in birds (D.E. Kroodsma \& E.H. Miller, eds). Cornell University Press, New York, p. 285-304.

Byrne, R.W. (1993). Do larger brains mean greater intelligence? - Behav. Brain Sci. 16, p. 696-697.

Carnduff, D. (1981). Black guillemots breeding in the inner Clyde estuary. — Scott. Birds 11, p. $195-196$.

Cohen, J. (1988). Statistical power analysis for the behavioral sciences. - Lawrence Erlbaum Associates, 2nd edn., New Jersey.

Collias, E.C. \& Collias, N.E. (1964). The development of nest - building behavior in a weaverbird. - The Auk 81, p. 42-52.

Dean, T. (1992). Nest cup of moorhen composed of polythene. - Br. Birds 85, p. 560.

Dunbar, R.I.M. (1998). The social brain hypothesis. - Evol. Anthr. 6, p. 178-190.

Hagemeijer, E.J.M. \& Blair, M.J. (1997). The EBCC atlas of european breeding birds: their distribution and abundance. - T. \& A.D. Poyser, London.

Hansell, M.H. (1984). Animal architecture and building behaviour. — Longman, London.

Harper, D. (1991). Wren excavating nest. — Br. Birds 84, p. 344.

Harvey, P.H. \& Pagel, M.D. (1991). The comparative method in evolutionary biology. Oxford University Press, Oxford.

Lefebvre, L., Gaxiola, A., Dawson, S., Timmermans, S., Rozsa, L. \& Kabai, P. (1998). Feeding innovations and forebrain size in Australasian birds. - Behaviour 135, p. 1077-1097.

— —, Whittle, P., Lascaris, E. \& Finkelstein, A. (1997). Feeding innovations and forebrain size in birds. - Anim. Behav. 53, p. 549-560.

Limbert, M. (1991). Sand martin and kingfisher nesting in peat-cuttings. — Br. Birds 84, p. 508-509.

McNeil, D.A.C. (1992). Use of house martin nests by blue tits for breeding. - Br. Birds 85, p. 314-315.

Meek, E.R. \& Little, B. (1980). Unusual nest sites of teal in Northumberland. — Br. Birds 73, p. 581.

Mitchell, J. (1985). Peregrines utilising wire nest of carrion crows. — Br. Birds 78, p. 593594.

Mitchell, R.W., Thompson, N.S. \& Miles, H.L. (1997). Anthropomorphism, anecdotes and animals. - State University of New York Press, Albany. 
Montier, D.J. (1980). Blackbirds, mistle thrushes and wheatears in roofed areas. - Br. Birds 73, p. 36-37.

Portmann, A. (1946). Etude sur la cérébralisation chez les oiseaux I. - Alauda 14, p. 2-20.

— — (1947). Etude sur la cérébralisation chez les oiseaux II. Les indices intra-cérébraux. Alauda 15, p. 1-15.

Purvis, A. \& Rambaut, A. (1995). Comparative analysis by independent contrasts (CAIC): an Apple Macintosh application for analysing comparative data. - Comp. Appl. Biosci. 11, p. 247-251.

Reader, S.M. \& Laland, K.N. (1999). Forebrain size, opportunism and the evolution of social learning in nonhuman primates. - Ethol. S34, p. 50.

Rebecca, G.W. (1988). Woodpigeons nesting on sea cliffs and inside buildings. — Br. Birds 81, p. $28-29$.

Sargent, T.D. (1965). The role of experience in the nest building of the zebra finch. - The Auk 82, p. 48-61.

Sherry, D.F., Jacobs, L.F. \& Gaulin, S.J.C. (1992). Spatial memory and adaptive specialization of the hippocampus. - Trends Neurosci. 15, p. 298-303.

Sibley, C.G. \& Ahlquist, J.E. (1990). Phylogeny and classification of birds: a study in molecular evolution. - Yale University Press, New Haven, CT.

— — \& Monroe, B.L. (1990). Distribution and taxonomy of birds of the world. - Yale University Press, New Haven, CT.

Smith, M.B. (1992). Peregrines nesting beside kestrels on urban chimney. - Br. Birds 85, p. 498.

Sol, D.L. \& Lefebvre, L. (in press). Forebrain size and foraging innovations predict invasion success in birds introduced to New Zealand. - Oikos.

Summers, R.W. (1989). Starlings excavating nest holes in sand dunes. - Scott. Birds 15, p. 181.

Trodd, P. (1993). Hobbies nesting on pylon. — Br. Birds 86, p. 625.

de Voogd, T.J., Krebs, J.R., Healy, S.D. \& Purvis, A. (1993). Relations between song repertoire size and the volume of brain nuclei related to song: comparative evolutionary analyses amongst oscine birds. — Proc. Roy. Soc. (B) 254, p. 75-82.

Watson, A. (1977). Exceptional red grouse nest made of straw. - Scott. Birds 9, p. 347-348.

- - (1982). Work on golden eagle and peregrine in northeast Scotland in 1981. - Scott. Birds 12, p. 54-55.

Whiten, A. \& Byrne, R.W. (1988). Tactical deception in primates. - Behav. Brain Sci. 11, p. 233-273.

Wyles, J.S., Kunkel, J.G. \& Wilson, A.C. (1981). Birds, behaviour and anatomical evolution. — Proc. Nat. Acad. Sci. (USA) 80, p. 4394-4397. 